\title{
Monitoring the Occurrence of Pain Symptoms in University Female Handball Players: A 12-Month Prospective Cohort Study
}

\author{
Sonoko Mashimo ${ }^{1 *}$, Naruto Yoshida ${ }^{2}$, Ayaka Takegami ${ }^{3}$, Yuki Warashina ${ }^{4}$, Hitoshi Shiraki ${ }^{4}$ \\ ${ }^{1}$ Institute for Liberal Arts and Sciences, Osaka Electro-Communication University, Osaka, Japan \\ ${ }^{2}$ Department of Acupuncture and Moxibustion, Faculty of Health Care, Teikyo Heisei University, Tokyo, Japan \\ ${ }^{3}$ Graduate School of Comprehensive Human Sciences, University of Tsukuba, Ibaraki, Japan \\ ${ }^{4}$ Faculty of Health and Sport Sciences, University of Tsukuba, Ibaraki, Japan
}

Received: November 15, 2018

Accepted: March 22, 2019

Published online: April 30, 2019

Keywords:

Handball

Pain

Physical load

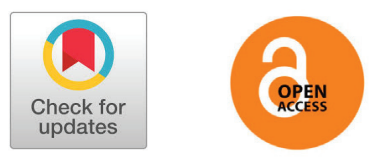

\section{ABSTRACT}

OBJECTIVES To understand the condition of athletes engaged in daily sports activities, it is important to investigate the pain that many such athletes can experience as well as the pain that can be an initial symptom of injury. Although handball is a contact sport associated with frequent injuries, the actual nature of pain symptoms that develop has not been sufficiently studied, and the relationship between pain occurrence and athletes' daily changing physical load remains unclear. This study aimed to clarify the nature of pain symptoms in handball players and examine the relationship between pain occurrence and physical load.

METHODS This study involved a 12-month daily assessment of pain symptoms and physical load involving 11 university female handball players. Pain was examined in terms of body region and a pain severity score using a pain questionnaire, and physical load on handball was assessed based on playing hours, types of matches and training recorded by a video camera.

RESULTS The total number of pains was 1698 , and the pain incidence rate was 288.1 pains per 1000 player hours. In terms of body regions, the ankle (18.3\%) was the most common, followed by the lower back (13.3\%), foot (12.8\%), Achilles tendon (9.2\%), and thigh (8.9\%). With regard to the relationship between pain and physical load, significant moderate or weak correlations were observed between handball $\left(r_{s}=0.657\right)$, training $\left(r_{s}=0.626\right)$, and on-court training $\left(r_{s}=0.591\right)$ and overall pain occurrences. In terms of body regions, the ankle and thigh, significant moderate or weak correlations were observed with respect to all categories in on-court training.

CONCLUSIONS We found that pain occur frequently and athletes continue to compete in games despite experiencing pain. In addition, pain occurrence was related to physical load, indicating that the type of physical load depends on the body region.

(c) The Asian Society of Kinesiology and the Korean Academy of Kinesiology

\section{Introduction}

Athletes train daily at a high intensity in attempt to achieve their best performance in competitions. High-intensity

*Correspondence: Sonoko Mashimo, Institute for Liberal Arts and Sciences, Osaka Electro-Communication University, 18-8 Hatsucho, Neyagawa, Japan; Tel: +81-72824-1131; Fax: +81-72-824-1141; E-mail: mashimo@osakac.ac.jp training has been reported to improve the physical ability of athletes in terms of aerobic capacity, high-intensity running ability, and body mass index; however, it can also increase the frequency of injuries and illnesses [1]. Because these negative outcomes arising from high-intensity training can lower athletes' performance and affect the success of individual 
athletes or their teams [2,3], it is important to monitor the condition of the athlete and prevent injuries and illnesses.

An athlete's condition consists of many factors, such as physical, environmental, and psychological factors. Among these factors, pain, a physical factor, has been reported to give rise to physical problems experienced by many athletes [4]. In addition, pain is an initial symptom of many types of injuries, and continuing to participate in training while experiencing pain may cause a decrease in performance, making it impossible to participate in training, further leading to more serious injuries over time (time loss injury) [5]. Thus, a greater understanding of pain experienced by athletes is important to injury prevention.

Handball is a high-intensity contact sport. In previous studies, high incidence rates of injuries were reported regardless of athlete age and level of competitiveness in handball [6-9]. Engebretsen et al. reported that handball had the highest injury risk in team sports tournaments during the 2004 Olympic Games [6]. Moreover, studies that targeted young handball players showed that the incidence of injury is as high as the senior level [7]. In contrast, pain that is not reached time-loss injury has been investigated by several studies. According to a study investigating symptoms from problem elbows for goalkeepers, more than $80 \%$ of all players reported that they had elbow pain in the present or the past [10]. In addition, the study on shoulder pain for female handball players reported that more than $50 \%$ of players had pain in the present or the past [11]. However, studies on pain normally specialized in some body parts, the actual extent of pain occurrences, which are the initial symptoms of many injuries, have not been adequately studied. Moreover, several studies have investigated the relationship between training load (physical load) and injuries in handball, and the frequency and body part of injury have been reported to vary by training period, which is determined by the amount of training and training type [12]. Further, Møller et al. demonstrated that a rapid increase in physical load increases the risk of shoulder injury in elite youth handball players [13]. However, the relationship between pain occurrence and changing daily physical load remains poorly understood. It is believed that clarifying these factors will help prevent injuries and facilitate conditioning throughout the season. Therefore, the purpose of this study was to clarify the actual extent of pain occurrences experienced by athletes and to examine the relationship between pain and physical load. We hypothesize based on a 12-month prospective cohort study that the degree of pain occurrence is related to an athlete's physical load and that the frequency and body part of pain vary with changes in physical load.

\section{Methods}

\section{Subjects}

Fourteen female handball players belonging to a university handball team participated in this study. Three of them did not complete the entire training because of injuries at the start of the study and who underwent rehabilitation for most of the investigation period were excluded. Therefore, the subjects were 11 female handball players (average age: $19.5 \pm 0.7$ years, average height: $164.0 \pm 4.9 \mathrm{~cm}$, average weight: $59.4 \pm 6.1 \mathrm{~kg}$, average years of handball experience: $8.0 \pm 2.7$ years). This team has a track record of winning at the All Japan Student Handball Championships, and each had a high level of skill and handball experience. This study was conducted with the approval of the university ethics committee (no.25-74), and informed written consent to participate in this study was obtained from each participant.

\section{Procedures}

We conducted a prospective cohort study to investigate pain occurrences, handball playing hours, and types of matches and training during the 12-month period from October 1, 2012, to September 30, 2013. The participants took part in daily handball matches and training planned by their head coach and responded to a questionnaire on pain.

\section{Pain Surveillance}

Pain was defined as "pain caused by participation in a handball match or training." Using the questionnaire, participants themselves described their pain experience every day. The questionnaire consisted of two items: body regions and a corresponding pain severity score. Pain severity scores consisted of a 6-point scale, with a score of 1 indicating the 
mildest pain and a score of 6 indicating the most severe pain (Table 1). If a player was unable to take a full part in match or training due to injury (time loss injury), the pain that occurred during that period was excluded from the analysis. To grasp the nature of pain experienced each day by the participants, all pain that occurred was counted as one case of pain. For example, if pain was experienced at two different body regions on the same day (e.g., shoulder pain and ankle pain), this was counted as two pains.

\begin{tabular}{ll} 
Table 1. & Pain severity score classification \\
\hline Score 1 & Pain after handball \\
Score 2 & Pain during handball that does not influence performance \\
Score 3 & $\begin{array}{l}\text { Pain during handball that sometimes influences } \\
\text { performance }\end{array}$ \\
Score 4 & Pain during handball that always influences performance \\
Score 5 & Pain during handball and all day long \\
Score 6 & $\begin{array}{l}\text { Pain during handball and all day long even though under } \\
\text { sleep }\end{array}$ \\
\hline
\end{tabular}

\section{Physical load on handball}

Physical load on handball was defined as "amount of playing hours of handball match and training." Using a video camera, we recorded the playing hours and types of matches and training each day for each participant. The types of physical load were classified into seven categories by the chief investigator and head coach (Figure 1) [12]. In handball, official matches such as league matches and tournaments were designated as "match," and others were designated as "training." With respect to training, we classified practices on the handball court as "on-court training" and practices outside the handball court as "off-court training." In addition, with respect to oncourt training, practice games under official rules is called "training match," practices specialized for handball other than training match were called "specialized training," and practices not related to handball such as dashing, stretching, and other types of ball games were taken as "general training." The total physical load calculated for each participant and physical load for each category were summed for all participants daily.

\section{Statistical methods}

The incidence rate of pain (1000 player hours) obtained by

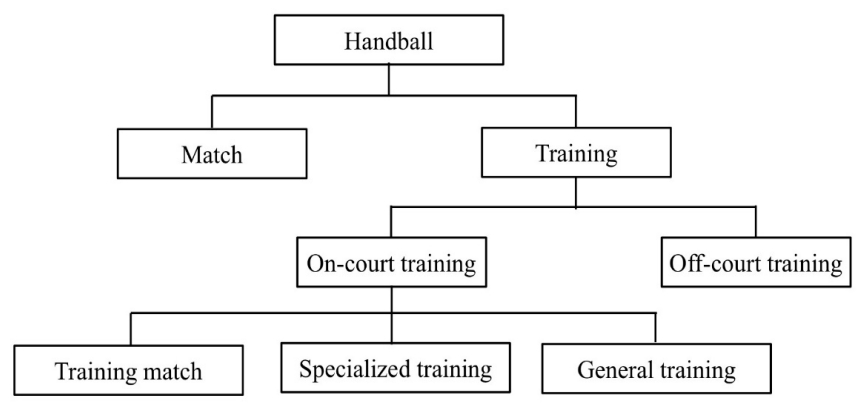

Figure 1. Classification of physical load types

dividing the number of pain occurrences by exposure (playing hours) was calculated and expressed with a $95 \%$ confidence interval (95\%CI) [14]. To determine the relationship between pain and physical load, Spearman's correlation coefficient was used for the number of pains daily and physical load. The correlation coefficients were defined as follows: very weak, 0 $\leq\left|r_{s}\right| \leq 0.20$; weak, $0.21 \leq\left|r_{s}\right| \leq 0.40$; moderate, $0.41 \leq\left|r_{s}\right| \leq$ 0.70 ; strong, $0.71 \leq\left|\mathrm{r}_{\mathrm{s}}\right| \leq 0.90$; and very strong, $0.91 \leq\left|\mathrm{r}_{\mathrm{s}}\right| \leq$ $1.00[15,16]$. The levels of significance for each item analyzed via Spearman's correlation coefficient were adjusted using the false discovery rate (FDR) [17]. SPSS Statistics software version 24.0 was used for all statistical analyses, and the level of statistical significance was set at $p=0.05$.

\section{Results}

\section{Pain}

Over the course of the 12-month survey, the total playing hours was 5893.6 hours, of which the match was 206.5 hours (24 days) and the training was 5687.1 hours (252 days). The total number of pains was 1698 , the pain incidence rate was 288.1 pains per 1000 player hours (95\% CI: 274.4-301.8). The characteristics of pain are described in Table 2 to Table 4 . In terms of body regions, the ankle ( $\mathrm{n}=311,18.3 \%)$ was the most common, followed by the lower back ( $\mathrm{n}=226,13.3 \%)$, foot ( $\mathrm{n}=218,12.8 \%)$, Achilles tendon ( $\mathrm{n}=157,9.2 \%)$, and thigh $(\mathrm{n}=151,8.9 \%)$. With regard to the score, score of $2(\mathrm{n}=751$, $44.2 \%$ ) was the most common, followed by 3 ( $n=331,19.5 \%$ ) and $5(n=326,19.2 \%)$. In terms of pain severity scores by body regions, score of 5 was the most frequent for the elbow 
$(\mathrm{n}=83,67.5 \%)$, sternum/ribs/upper back $(\mathrm{n}=18,60.0 \%)$, and foot $(n=91,41.7 \%)$ and score of 2 was the most common for other parts.

\section{Physical load on handball}

Table 5 shows the physical load over the 12-month period. During the study period, the overall physical load was 5893.6

Table 2. Match, training and pain incidence rate profiles for each subject

\begin{tabular}{|c|c|c|c|c|c|c|c|c|c|}
\hline \multirow{2}{*}{$\begin{array}{c}\text { Subject } \\
1\end{array}$} & \multicolumn{2}{|c|}{$\begin{array}{l}\text { Match hours } \\
\text { (days) }\end{array}$} & \multicolumn{2}{|c|}{$\begin{array}{l}\text { Training hours } \\
\text { (days) }\end{array}$} & \multicolumn{2}{|c|}{$\begin{array}{l}\text { Total playing hours } \\
\text { (days) }\end{array}$} & \multirow{2}{*}{$\begin{array}{c}\begin{array}{c}\text { Number of } \\
\text { pains }\end{array} \\
371\end{array}$} & \multirow{2}{*}{$\begin{array}{c}\text { Pain incidence rate } \\
\text { (1000 player hours) }\end{array}$} & \multirow{2}{*}{$\begin{array}{r}95 \% \mathrm{Cl} \text { for pain } \\
\text { incidence rate }\end{array}$} \\
\hline & 22.0 & $(21)$ & 546.6 & $(201)$ & 568.6 & $(222)$ & & & \\
\hline 2 & 22.0 & $(21)$ & 535.2 & (199) & 557.2 & (220) & 170 & 305.1 & 259.2 to 351.0 \\
\hline 3 & 22.0 & $(21)$ & 482.4 & (178) & 504.4 & (199) & 312 & 618.6 & 550.0 to 687.2 \\
\hline 4 & 25.0 & (24) & 622.7 & (238) & 647.7 & $(262)$ & 206 & 318.0 & 274.6 to 361.5 \\
\hline 5 & 9.0 & (8) & 266.4 & $(101)$ & 275.4 & (109) & 14 & 50.8 & 24.2 to 77.5 \\
\hline 6 & 22.0 & (21) & 598.0 & (239) & 620.0 & $(260)$ & 59 & 95.2 & 70.9 to 119.5 \\
\hline 7 & 9.5 & (10) & 376.1 & (145) & 385.6 & (155) & 76 & 197.1 & 152.8 to 241.4 \\
\hline 8 & 18.0 & (18) & 634.1 & $(247)$ & 652.1 & $(265)$ & 56 & 85.9 & 63.4 to 108.4 \\
\hline 9 & 24.0 & (23) & 644.8 & $(246)$ & 668.8 & (269) & 90 & 134.6 & 106.8 to 162.4 \\
\hline 10 & 19.0 & (19) & 614.7 & (238) & 633.7 & (257) & 288 & 454.5 & 402.0 to 507.0 \\
\hline 11 & 14.0 & (14) & 366.3 & (148) & 380.3 & $(162)$ & 56 & 147.3 & 108.7 to 185.8 \\
\hline Total & 206.5 & (24) & 5687.1 & $(252)$ & 5893.6 & $(276)$ & 1698 & 288.1 & 274.4 to 301.8 \\
\hline
\end{tabular}

Table 3. Proportion of body regions by pain severity score

\begin{tabular}{|c|c|c|c|c|c|c|c|c|c|c|c|c|c|}
\hline \multirow[b]{2}{*}{ Head and neck } & \multicolumn{2}{|c|}{ Score 1} & \multicolumn{2}{|c|}{ Score 2} & \multicolumn{2}{|c|}{ Score 3} & \multicolumn{2}{|c|}{ Score 4} & \multicolumn{2}{|c|}{ Score 5} & \multicolumn{2}{|c|}{ Score 6} & \multirow{2}{*}{$\begin{array}{c}\text { Total } \\
1\end{array}$} \\
\hline & 0 & $(0 \%)$ & 1 & $(100 \%)$ & 0 & $(0 \%)$ & 0 & $(0 \%)$ & 0 & $(0 \%)$ & 0 & $(0 \%)$ & \\
\hline Shoulder & 14 & (11.2\%) & 64 & $(51.2 \%)$ & 36 & $(28.8 \%)$ & 0 & $(0 \%)$ & 11 & (8.8\%) & 0 & $(0 \%)$ & 125 \\
\hline $\begin{array}{l}\text { Upper arm/ } \\
\text { lower arm }\end{array}$ & 0 & $(0 \%)$ & 1 & $(50.0 \%)$ & 1 & $(50.0 \%)$ & 0 & $(0 \%)$ & 0 & (0\%) & 0 & $(0 \%)$ & 2 \\
\hline Elbow & 0 & $(0 \%)$ & 13 & (10.6\%) & 24 & $(19.5 \%)$ & 3 & $(2.4 \%)$ & 83 & (67.5\%) & 0 & $(0 \%)$ & 123 \\
\hline Wrist & 0 & $(0 \%)$ & 37 & (53.6\%) & 22 & (31.9\%) & 0 & $(0 \%)$ & 10 & $(14.5 \%)$ & 0 & $(0 \%)$ & 69 \\
\hline Finger & 2 & $(1.9 \%)$ & 70 & $(66.0 \%)$ & 18 & (17.0\%) & 3 & $(2.8 \%)$ & 3 & $(2.8 \%)$ & 10 & $(9.4 \%)$ & 106 \\
\hline $\begin{array}{l}\text { Sternum/ribs/ } \\
\text { upper back }\end{array}$ & 1 & $(3.3 \%)$ & 10 & $(33.3 \%)$ & 1 & $(3.3 \%)$ & 0 & $(0 \%)$ & 18 & $(60.0 \%)$ & 0 & $(0 \%)$ & 30 \\
\hline Abdomen & 2 & $(40.0 \%)$ & 3 & $(60.0 \%)$ & 0 & $(0 \%)$ & 0 & $(0 \%)$ & 0 & $(0 \%)$ & 0 & $(0 \%)$ & 5 \\
\hline Lower back & 61 & $(27.0 \%)$ & 85 & $(37.6 \%)$ & 48 & $(21.2 \%)$ & 4 & $(1.8 \%)$ & 28 & $(12.4 \%)$ & 0 & $(0 \%)$ & 226 \\
\hline Hip/groin & 4 & (21.1\%) & 8 & $(42.1 \%)$ & 3 & (15.8\%) & 0 & $(0 \%)$ & 3 & $(15.8 \%)$ & 1 & $(5.3 \%)$ & 19 \\
\hline Thigh & 15 & $(9.9 \%)$ & 66 & $(43.7 \%)$ & 35 & $(23.2 \%)$ & 5 & $(3.3 \%)$ & 30 & (19.9\%) & 0 & $(0 \%)$ & 151 \\
\hline Knee & 7 & $(10.8 \%)$ & 30 & $(46.2 \%)$ & 14 & $(21.5 \%)$ & 3 & $(4.6 \%)$ & 11 & $(16.9 \%)$ & 0 & $(0 \%)$ & 65 \\
\hline Lower leg & 6 & $(6.7 \%)$ & 53 & $(58.9 \%)$ & 17 & $(18.9 \%)$ & 2 & $(2.2 \%)$ & 12 & $(13.3 \%)$ & 0 & $(0 \%)$ & 90 \\
\hline Achilles tendon & 8 & $(5.1 \%)$ & 96 & $(61.1 \%)$ & 22 & $(14.0 \%)$ & 12 & $(7.6 \%)$ & 18 & $(11.5 \%)$ & 1 & $(0.6 \%)$ & 157 \\
\hline Ankle & 103 & $(33.1 \%)$ & 139 & $(44.7 \%)$ & 57 & $(18.3 \%)$ & 4 & $(1.3 \%)$ & 8 & $(2.6 \%)$ & 0 & $(0 \%)$ & 311 \\
\hline Foot & 15 & $(6.9 \%)$ & 75 & $(34.4 \%)$ & 33 & $(15.1 \%)$ & 1 & $(0.5 \%)$ & 91 & $(41.7 \%)$ & 3 & $(1.4 \%)$ & 218 \\
\hline Total & 238 & (14.0\%) & 751 & (44.2\%) & 331 & (19.5\%) & 37 & $(2.2 \%)$ & 326 & (19.2\%) & 15 & $(0.9 \%)$ & 1698 \\
\hline
\end{tabular}




\begin{tabular}{lcc}
\multicolumn{3}{l}{ Table 4. Distribution of pain body regions } \\
Body region & Number of pains & $\%$ \\
\hline Head and neck & 1 & 0.1 \\
Shoulder & 125 & 7.4 \\
Upper arm/lower arm & 2 & 0.1 \\
Elbow & 123 & 7.2 \\
Wrist & 69 & 4.1 \\
Finger & 106 & 6.2 \\
Sternum/ribs/upper back & 30 & 1.8 \\
Abdomen & 5 & 0.3 \\
Lower back & 226 & 13.3 \\
Hip/groin & 19 & 1.1 \\
Thigh & 151 & 8.9 \\
Knee & 65 & 3.8 \\
Lower leg & 90 & 5.3 \\
Achilles tendon & 157 & 9.2 \\
Ankle & 311 & 18.3 \\
Foot & 218 & 12.8 \\
\hline Total & 1698 & 100 \\
\hline & &
\end{tabular}

hours, of which matches comprised 206.5 hours (3.5\%) and training comprised 5687.1 hours (96.5\%). Average daily physical load was 16.2 hours in overall physical load, and 0.6 hours in match and 15.6 hours in training. For training, oncourt training was 4431.6 hours (77.9\%) and off-court training was 1255.5 hours (22.1\%). In terms of average daily physical load, on-court training was 12.1 hours and off-court training was 3.4 hours. In addition, during on-court training, the training match was 894.7 hours $(20.2 \%)$, specialized training was 2798.7 hours (63.2\%), and general training was 738.3 hours (16.7\%). Average daily physical load was 2.5 hours in training match, 7.7 hours in specialized training, and 2.0 hours in general training.

\section{Relationship between pain and physical load}

Table 6 shows the relationship (correlation coefficient) between the number of pain occurrences per day and physical load. Significant moderate correlations were observed between handball $\left(r_{s}=0.657\right)$, training $\left(r_{s}=0.626\right)$, on-court training $\left(r_{s}=0.591\right)$, specialized training $\left(r_{s}=0.588\right)$ and overall pain occurrences. In addition, significant weak correlations were observed between overall pain occurrences and training match

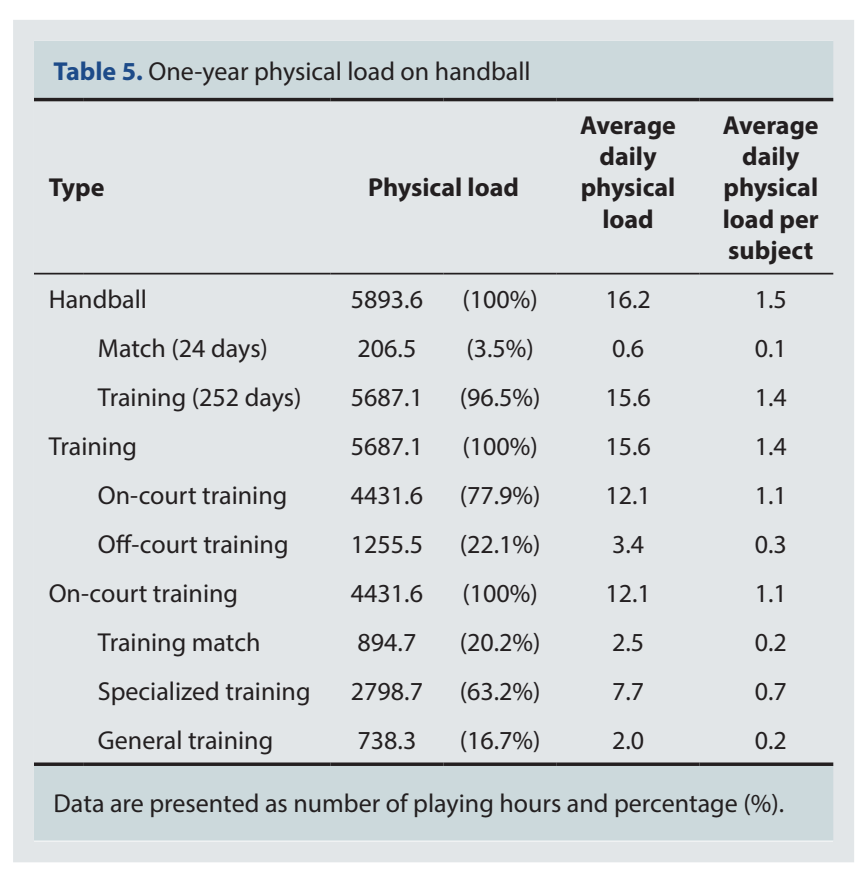

$\left(r_{s}=0.356\right)$ and general training $\left(r_{s}=0.364\right)$. For body regions, in the ankle, significant moderate correlations were observed between handball $\left(r_{s}=0.504\right)$, training $\left(r_{s}=0.481\right)$, on-court training $\left(r_{s}=0.499\right)$, and specialized training $\left(r_{s}=0.510\right)$, and significant weak correlations were observed between training match $\left(r_{s}=0.230\right)$ and general training $\left(r_{s}=0.396\right)$. Significant moderate correlations were observed between the lower back and handball $\left(r_{s}=0.433\right)$ and training $\left(r_{s}=0.410\right)$; significant weak correlations were observed between on-court training $(\mathrm{rs}=0.342)$, specialized training $\left(r_{s}=0.378\right)$, and general training $\left(r_{s}=0.227\right)$. Moreover, significant weak correlations were observed between foot and handball $\left(r_{s}=0.222\right)$ and specialized training $\left(r_{s}=0.210\right)$.

\section{Discussion}

Over the course of this 12-month prospective cohort study in female university handball team, many pain symptoms occurred, and it became clear that athletes continue to compete in games despite experiencing pain. In addition, pain occurrence was found to be related to physical load, indicating a relationship with on-court training in particular. Furthermore, the types of physical load differ by body region of pain occurrence.

The overall pain incidence rate was 288.1 pains/1000 player 


\begin{tabular}{|c|c|c|c|c|c|c|c|c|}
\hline & Handball & Match & Training & $\begin{array}{l}\text { On-court } \\
\text { training }\end{array}$ & $\begin{array}{l}\text { Off-court } \\
\text { training }\end{array}$ & $\begin{array}{l}\text { Training } \\
\text { match }\end{array}$ & $\begin{array}{l}\text { Specialized } \\
\text { training }\end{array}$ & $\begin{array}{l}\text { General } \\
\text { training }\end{array}$ \\
\hline Head and neck & 0.084 & -0.014 & 0.084 & 0.087 & -0.037 & 0.113 & 0.081 & 0.024 \\
\hline Shoulder & $0.357^{*}$ & 0.089 & $0.345^{*}$ & $0.305^{*}$ & $0.144^{*}$ & $0.139^{*}$ & $0.333^{*}$ & $0.179^{*}$ \\
\hline Upper arm/lower arm & 0.035 & -0.020 & 0.036 & 0.032 & 0.027 & -0.037 & 0.047 & 0.074 \\
\hline Elbow & 0.101 & $0.163^{*}$ & 0.068 & 0.084 & -0.005 & 0.099 & 0.068 & -0.055 \\
\hline Wrist & $0.239^{*}$ & -0.006 & $0.245^{*}$ & $0.246^{*}$ & 0.011 & $0.249^{*}$ & $0.209^{*}$ & $0.146^{*}$ \\
\hline Finger & $0.407^{*}$ & 0.070 & $0.383^{*}$ & $0.372^{*}$ & 0.030 & $0.232^{*}$ & $0.367^{*}$ & $0.256^{*}$ \\
\hline Sternum/ribs/upper back & $0.127^{*}$ & 0.087 & 0.108 & 0.118 & 0.022 & -0.039 & $0.164^{*}$ & 0.084 \\
\hline Abdomen & 0.082 & $0.163^{*}$ & 0.049 & 0.058 & 0.051 & 0.045 & 0.075 & -0.009 \\
\hline Lower back & $0.433^{*}$ & 0.115 & $0.410^{*}$ & $0.342^{*}$ & $0.184^{*}$ & $0.139^{*}$ & $0.378^{*}$ & $0.227^{*}$ \\
\hline Hip/groin & 0.048 & 0.037 & 0.044 & 0.028 & 0.090 & 0.000 & 0.043 & 0.032 \\
\hline Thigh & $0.427^{*}$ & -0.034 & $0.426^{*}$ & $0.375^{*}$ & 0.114 & $0.232^{*}$ & $0.369^{*}$ & $0.278^{*}$ \\
\hline Knee & $0.210^{*}$ & 0.029 & $0.212^{*}$ & $0.166^{*}$ & 0.097 & $0.124^{*}$ & $0.156^{*}$ & $0.152^{*}$ \\
\hline Lower leg & $0.270^{*}$ & 0.083 & $0.248^{*}$ & $0.235^{*}$ & 0.032 & $0.180^{*}$ & $0.226^{*}$ & $0.145^{*}$ \\
\hline Achilles tendon & $0.248^{*}$ & 0.033 & $0.241^{*}$ & $0.252^{*}$ & -0.012 & $0.147^{*}$ & $0.244^{*}$ & 0.120 \\
\hline Ankle & $0.504^{*}$ & $0.179^{*}$ & $0.481^{*}$ & $0.499^{*}$ & 0.090 & $0.230^{*}$ & $0.510^{*}$ & $0.396^{*}$ \\
\hline Foot & $0.222^{*}$ & $0.199^{*}$ & $0.194^{*}$ & $0.194^{*}$ & 0.113 & $0.136^{*}$ & $0.210^{*}$ & 0.028 \\
\hline Total & $0.657^{*}$ & $0.171^{*}$ & $0.626^{*}$ & $0.591^{*}$ & $0.153^{*}$ & $0.356^{*}$ & $0.588^{*}$ & $0.364^{*}$ \\
\hline
\end{tabular}

hours. This incidence rate is high and it is clear that many handball players continue playing despite experiencing pain, which was not captured through handball injury surveys. The injury definition of "medical attention" and/or "time loss" was used when recording injuries in injury surveys. Medical attention injury is an injury that results in a player receiving medical attention by a qualified medical practitioner, and time loss injury is an injury that results in a player being unable to completely participate in future training or match play [18]. Therefore, pain that does not require medical attention or does not result in time loss is not recorded in these injury surveys.

With regard to body regions, the ankle was the most frequently affected body part, followed by the lower back and foot. In the handball injury survey, the ankle is the main body region where injury commonly occurs [19-21]. As the body regions in this study were also similar, it can be said that ankle injuries and pains are inherent in handball. Previous studies have reported that the lower back is one of the body parts where overuse injury often occurs in handball $[7,22,23]$. According to a 13-week injury survey study targeting elite
Norwegian handball players, $12 \%$ of all players had physical problems including pain in the lower back throughout the study period. It was reported that the prevalence rates of lower back problems, as well as knee and shoulder problem were high [23].

By looking at pain severity based on the severity score, approximately half of the cases had a score of "2," which describes pain but not of a degree that affect performance, with respect to overall pain occurrence. From this, we believe that it is important to prevent mild pain from progressing to pain that may affect an athlete's performance (score of 3 or higher in this study). In contrast, $40 \%$ (score3-6) of overall pain occurrence affected the performance. Among them, it became clear that $53.3 \%$ of the pain (score4-6) always restricted the athlete's performance. In terms of body regions, score of 5 was the most common at the elbow, sternum/ribs/ upper back, and foot and score of 2 was the most common for other parts. In particular, elbow pain with a score of 5 accounted for $67.5 \%$. An epidemiological study concerning elbow problems in handball shows that roughly $30 \%$ of field 
player have elbow problems such as pain in the past and/ or present [24]. Moreover, the main mechanism of elbow problems for field players is repetitive overhead throwing, mainly in the throwing arm. As approximately two-thirds were severe pain (score of 5), future study is needed to investigate further the mechanism.

In relation to pain occurrence and physical load, the overall pain occurrence was related to physical load, in which moderate or weak correlations were observed with respect to all categories in on-court training. This indicates that when the daily number of pain occurrences and physical load are observed over time, the number of pain episodes increases as the number of on-court training hours increase. In terms of body regions, the ankle and thigh also exhibited the same tendencies and correlated with all categories with respect to on-court training. In addition, the lower back had weak correlations with specialized training and general training. By contrast, pain occurrences in the foot and Achilles tendon were low and correlated only with specialized training among on-court training. Based on these results, it is necessary to introduce preventive measures that incorporate changes in physical loads because the relevant categories differ depending on the body parts that experience pain.

The present study's major strength is that it investigated the actual extent of pain occurrences experienced by athletes which are not captured in handball injury surveys. However, there are some limitations in this study. The primary limitation was the small number of participants. As we used paper questionnaire as medium to capture pain occurrence and video camera to measure physical load, the investigator had to distribute the questionnaire and record handball match and training every day. For this reason, the participants were only from one handball team. Therefore, findings in this study may be applicable only to university female handball team. Future studies are needed to improve our methodological approach, for example use of web-based questionnaire, and to include sufficient sample size.

Another limitation was that we investigated only the body part and severity score in the whole body by self-reported questionnaire in pain occurrence. Thus, the mechanism and pathology of pain are not yet clear. Information about the type of movement or activity in which the pain occurred is important when introducing preventative measures. In addition, subjective pain was investigated using a self-reported questionnaire in previous studies of pain in handball $[10,11]$. According to the definition of International Association for the Study of Pain, pain is defined as an unpleasant sensory and emotional experience and is always subjective [25]. Based on the results of these previous studies, we subjectively assessed the pain that handball players experienced. However, it is important for pain and injury prevention to understand both subjective pain and the pathology of pain objectively. Furthermore, it was revealed that overuse injuries in handball frequently occur in the lower back and shoulder. Overuse injuries usually start with mild pain, and then gradually progress to severe pain [5]. If we can assess pain objectively using for example a doctor's diagnosis, we need to focus on these body parts and consider the transition from pain to injury. Therefore, future study is needed to investigate mechanism of pain, evaluate the pain objectively and focus on the body parts where overuse injuries often occurred.

Furthermore, the amount of playing hours was used as physical load in this study. In recent years, studies that have focused on the relationship between physical load and injuries have been actively conducted in various sports. According to the study that summarize variables used in physical loadinjury investigations [26], session-rating of perceived exertion (sRPE) was most used, followed by global positioning system (GPS) and then hours. In particular, the measurements with sRPE and GPS can consider not only volume but also intensity of physical load. In handball, previous studies on the relationship between physical load and injuries used playing hours as physical load $[12,13]$. We also used playing hours as a variable of physical load, but it measured only the volume of load. Therefore, it is necessary to consider physical load including intensity in the future.

\section{Conclusions}

We found that pain occur frequently and that athletes continue to compete despite experiencing pain. $40 \%$ of overall pain occurrence affected the athlete's performance, 53.3\% 
of which showed that performance was always limited by pains. In addition, pain occurrence is related to physical load, especially related to on-court training. Within the different body regions, it was shown that the categories of physical load related to body regions differed during on-court training.

\section{Acknowledgments}

The author would like to thank the handball players and coaches involved in the research.

\section{Conflicts of Interest}

The authors declare no conflict of interest.

\section{References}

1. Gabbett TJ, Ullah S. Relationship between running loads and soft-tissue injury in elite team sport athletes. J Strength Cond Res. 2012; 26(4):953-960.

2. Anderson L, Triplett-McBride T, Foster C, Doberstein S, Brice G. Impact of training patterns on incidence of illness and injury during a women's collegiate basketball season. J Strength Cond Res. 2003; 17(4):734-738.

3. Wilson F, Gissane C, Gormley J, Simms C. A 12-month prospective cohort study of injury in international rowers. Br J Sports Med. 2010; 44(3):207-214.

4. Bahr R. No injuries, but plenty of pain? On the methodology for recording overuse symptoms in sports. Br J Sports Med. 2009; 43(13):966-972.

5. Hespanhol Junior LC, Barboza SD, van Mechelen W, Verhagen E. Measuring sports injuries on the pitch: a guide to use in practice. Brazilian J Phys Ther. 2015; 19(5):369-380.

6. Engebretsen L, Soligard T, Steffen K, et al. Sports injuries and illnesses during the London Summer Olympic Games 2012. Br J Sports Med. 2013; 47(7):407-14.

7. Olsen O-E, Myklebust G, Engebretsen L, Bahr R. Injury pattern in youth team handball: a comparison of two prospective registration methods. Scand J Med Sci Sports. 2006; 16(6):426-432.

8. Langevoort G, Myklebust G, Dvorak J, et al. Handball injuries during major international tournaments. Scand J Med Sci Sports. 2007; 17(4):400-407.

9. Giroto N, Hespanhol Junior LC, Gomes MRC, Lopes AD. Incidence and risk factors of injuries in Brazilian elite handball players: A prospective cohort study. Scand J Med Sci Sports. 2017; 27(2):195-202.

10. Tyrdal S, Bahr R. High prevalence of elbow problems among goalkeepers in European team handball -“handball goalie's elbow”. Scand J Med Sci Sports. 1996; 6(5):297-302.

11. Myklebust G, Hasslan L, Bahr R, et al. High prevalence of shoulder pain among elite Norwegian female handball players. Scand J Med Sci Sports. 2013; 23(3):288-294.

12. Mashimo S, Warashina Y, Shiraki H, Miyakawa S. A study of cases of injury and pain in a women's college handball team. Japanese J Clin Sport Med. 2016; 24(2):244-253.

13. Møller M, Nielsen RO, Attermann J, et al. Handball load and shoulder injury rate: a 31-week cohort study of 679 elite youth handball players. Br J Sports Med. 2017; 51(4):231-7.

14. Knowles SB, Marshall SW, Guskiewicz KM. Issues in estimating risks and rates in sports injury research. J Athl Train. 41(2):207-215.

15. William B, Elizabeth AB, Daniel WW. Leading Without Authority: An Examination of the Impact of Transformational Leadership Cooperative Extension Work Groups and Teams. J Ext. 1996; 34(5): Unpaged.

16. Guilford JP. Fundamental statistics in phychology and education. New York: mcGraw Hill. 1956.

17. Matsuda S. Introduction of FDR and comparisons of multiple testing procedures that control it. Japanese J Biometrics. 2008; 29(2):125-139.

18. Fuller CW1, Ekstrand J, Junge A, et al. Consensus statement on injury definitions and data collection procedures in studies of football (soccer) injuries. Br J Sport Med. 2006; 40(3):193-201.

19. Andrén-Sandberg A, Lindstrand A. Injuries sustained in junior league handball. A prospective study of validity in the registration of sports injuries. Scand J Soc Med. 1982; 10(3):101-4. 
20. Nielsen A, Yde J. An Epidemiologic and Traumatologic Study of Injuries in Handball. Int J Sports Med.1988; 09(05):341-4.

21. Moller M, Attermann J, Myklebust G, Wedderkopp N. Injury risk in Danish youth and senior elite handball using a new SMS text messages approach. Br J Sports Med. 2012; 46(7):531-7.

22. Seil R, Rupp S, Tempelhof S, Kohn D. Sports injuries in team handball. A one-year prospective study of sixteen men's senior teams of a superior nonprofessional level. Am J Sports Med. 26(5):681-687.

23. Clarsen B, Bahr R, Heymans MW, et al. The prevalence and impact of overuse injuries in five Norwegian sports: Application of a new surveillance method. Scand J Med
Sci Sports. 2015; 25(3):323-30.

24. Popovic N, Ferrara MA, Daenen B, et al. Imaging overuse injury of the elbow in professional team handball players: a bilateral comparison using plain films, stress radiography, ultrasound and magnetic imaging. Int J Sports Med. 2001; 22:60-67.

25. International Association for the Study of Pain Press. Classification of chronic pain. Merskey and Bogduk, 1994, p 209-214.

26. Windt J, Ardern CL, Gabbett TJ, et al. Getting the most out of intensive longitudinal data: a methodological review of workload-injurystudies. BMJ Open. 2018; 8(10):1-17. 